\title{
Teatro popular de títeres de Barriga Verde: a patrimonialización imposíbel
}

\author{
Comba Campoi García ${ }^{1}$
}

Recibido: 16 de xuño de 2019 / Aceptado: 3 de febreiro de 2020

Resumo. Os movementos de base que reclaman que os bens propios das clases populares sexan considerados como patrimonio cultural inmaterial fano coa positiva intención de preservar e lexitimar esas formas de cultura, poñendo en valor procesos de creación artística que tradicionalmente foron minusvalorados pola Academia. Un exemplo disto constitúeo Barriga Verde, espectáculo de títeres tradicionais que gozou de grande popularidade en Galiza até 1964. O seu carácter eminentemente subversivo, na liña da tradición europea da que provén, fai del un ben cultural pouco atractivo para quen entende o patrimonio como unha forma de xerar beneficios económicos á marxe do significado orixinal dos bens explotados. A Asociación Cultural Morreu o Demo está a traballar xustamente en revivir o espectáculo sen necesidade de encerralo na categoría patrimonial.

Palabras chave: teatro popular; monicreques; patrimonio cultural inmaterial; resistencia simbólica.

\section{[es] Teatro popular de títeres de Barriga Verde: la patrimonialización imposible}

Resumen. Los movimientos de base que reclaman para los bienes propios de las clases populares la consideración como patrimonio cultural inmaterial lo hacen con la positiva intención de preservar y legitimar esas formas de cultura, poniendo en valor procesos de creación artística que tradicionalmente fueron minusvalorados por la Academia. Un ejemplo de ello lo constituye Barriga Verde, espectáculo de títeres tradicionales que disfrutó de gran popularidad en Galicia hasta 1964. Su carácter eminentemente subversivo, en la línea de la tradición europea de la que proviene, hace de él un bien cultural poco atractivo para quien entiende el patrimonio como una forma de generar beneficios económicos al margen del significado original de los bienes explotados. La Asociación Cultural Morreu o Demo está trabajando justamente en revivir el espectáculo sin necesidad de encerrarlo en la categoría patrimonial.

Palabras clave: teatro popular; marionetas; patrimonio cultural inmaterial; resistencia simbólica.

\section{[en] Barriga Verde Popular Puppets Theatre: the Impossible Patrimonialization}

Abstract. Grassroots movements that claim that the culture of popular classes has to be included in the intangible cultural heritage label, do so with the positive intention of preserving and legitimizing those forms of culture. By doing so, they intend to give value to creative processes that were traditionally undervalued by the Academy. An example of this is Barriga Verde, a traditional puppet show that enjoyed great popularity in Galicia until 1964. Its eminently subversive character, in line with the European tradition from which it comes, makes it an unattractive cultural asset for those who understands heritage as a way to generate economic benefits regardless of the original meaning of the assets exploited. The Cultural Association "Morreu o Demo" is working precisely to revive the show without having to enclose it into heritage category.

Keywords: Popular Theatre; Puppets; Intangible Cultural Heritage; Symbolic Resistance.

Sumario. 1. Introdución. 2. Rastrexar a tradición. 3. Un medio de comunicación das subalternas. 4. O resto dun tempo ido. 4.1. Primeira fase do proceso de activación patrimonial. 4.2. Segunda fase do proceso de activación patrimonial. 5. O patrimonio en cuestión. 6. Activismo vs. máquina patrimonial. 7. Referencias bibliográficas.

Como citar: Campoi García, C. (2020): "Barriga Verde: a patrimonialización imposíbel”, en Madrygal. Revista de Estudios Gallegos 23 Núm. Especial, pp. 51-59.

1 Consellería de Educación, Xunta de Galicia.

Correo-e: combac@edu.xunta.es. 


\section{Introdución}

Este texto ten o carácter volátil dunha función de fantoches populares: a súa materia é intanxíbel e a cuestión que trata de pór sobre a mesa atópase en progreso. Do mesmo xeito, os espectáculos do teatro popular de títeres de luva bebían do contexto inmediato, do momento e o lugar da representación, sen partir nunca dunha versión escrita e inamovíbel. Mais, salvando esa barreira de partida, o fin último deste texto é facer partícipe á comunidade estudosa da cultura galega dun debate en marcha arredor dun obxecto de estudo que se resiste a ser tratado como tal. Se a noción de patrimonio ten sido usada e abusada desde distintos intereses en relación a bens e símbolos da cultura galega, hoxe son diversas as voces que cuestionan, non só a utilización do termo como fonte de riqueza ou de reivindicación identitaria, mais a noción de patrimonio en si mesma. E, no marco dese debate, Barriga Verde, para quen ninguén reclamou nunca o estatuto patrimonial, emerxe como peza esquecida e incómoda.

O presente texto trata de confrontar a reflexión teórica, a partir da investigación sobre o papel do espectáculo de títeres de Barriga Verde como medio de comunicación das subalternas (Campoi 2018), expresión da resistencia simbólica durante o Franquismo; coa experiencia de traballo activista na Asociación Cultural Morreu o Demo para recuperar, divulgar e socializar este legado cultural.

\section{Rastrexar a tradición}

Falamos de "sen pegadas", parafraseando a Bernardot (2011), para nos referir a aqueles colectivos que non puxeron interese en deixar rexistro do seu paso, refuxiados no anonimato como estratexia defensiva. Colectivos que, nalgúns casos, vivían de xeito itinerante, evitando apousar en ningún lugar, xerando lazos comunitarios só entre aquelas que compartían o trazo característico da transhumancia e as marxes (Rao 1985). Recuperar un ben cultural dos grupos subalternos supón moitas veces unha tarefa de prospección arqueolóxica, de rastrexo detectivesco no que con frecuencia os únicos rexistros proveñen do poder, caso de actas xudiciais, comunicacións de embargo, rexistros de nacemento ou de defunción.

No caso de Barriga Verde, o derradeiro exponente do teatro popular de títeres de luva en Galiza, a súa xenealoxía tampouco responde a un relato unívoco. Podemos encadrar o personaxe nunha tradición que arrinca no século XVI en Nápoles coa figura de Pulcinella, arquetipo da commedia dell'arte que segundo algunhas teorías foi o sucesor de Maccus, un dos heroes das farsas atelanas que parodiaban os abusos dos poderosos na Roma antiga (Montano 2003).

Pulcinella, heroe irreverente, foi ademais de máscara monicreque de luva, na súa forma máis humilde. Malia non ter acadado o prestixio da commedia dell'arte, que chegou a representarse nos salóns da aristocracia europea, os titiriteiros italianos que percorrían os camiños conseguiron burlar mellor a censura que acabaría coas farsas italianas no século XVII. Así, se en 1697 os comediantes italianos son definitivamente expulsados de París, Pulcinella quedou instalado nos teatriños das feiras de Saint Germain e do Pont Neuf, onde continuarían a parodiar aos poderosos (Magnin 1862). Seguindo procesos parellos, Pulcinella acabou sementando en toda Europa o seu carácter vivo e antiautoritario. O éxito do personaxe, co que as clases populares se identificaban, fixo que lle xurdisen numerosos parentes que falaban outras linguas e posuían trazos diferenciados en función de cada lugar. Naceron así os personaxes de Polichinelle na Franza, Punch no Reino Unido ou Kaspar nos países de fala alemá. Na península Ibérica adoptaría trazos particulares e na corte madrileña chamáronlle Don Cristóbal Polichinela, un nome de resonancias señoriais que chocaba co carácter grotesco do personaxe que encarnaba. A medida que o monicreque abandonaba as terras capitalinas ía adoptando trazos máis populares, e así en Andalucía coñecían como cristobita ao títere de luva manipulado polos titiriteiros ambulantes. Así chegaría aos tempos de Lorca, quen tivo a ocasión de asistir cando era neno ao espectáculo, rendéndolle anos despois homenaxe no seu Retablillo de Don Cristóbal (1930). En Galiza, as clases populares adoptaron o nome familiar de Cristovo para nomear o heroe que protagonizaba as breves escenas representadas polos cegos monifateiros nas feiras e romarías. En Portugal bautizaríano como Dom Roberto, arraigando de tal xeito que o pobo acabou usando os robertos como sinónimo de fantoches, do mesmo xeito que pasaba na Galiza cos cristovos ou en Franza cos guiñois. Esa familiaridade co espectáculo, exento de maiúsculas e de autorías estelares, vén dada polo seu carácter eminentemente popular. Era un tipo de teatro flexible, que se representaba nas prazas e nos camiños 
cun dispositivo simple. Unha saba ou pano ocultaba o corpo do titiriteiro, un artista popular que manexaba os títeres erguendo os brazos por riba da súa cabeza. Valíase dunha palleta, un pequeno artefacto feito con dúas láminas de prata atadas cun anaco de tea, que colocaba no padal brando para amplificar e distorsionar a súa voz, conseguindo así destacar entre o barullo da multitude e dotar o personaxe dunha aura sobrenatural (Campoy 2014). Unha axudante, que moitas veces interactuaba cos monicreques, pasaba unha bandexa ou chapeu ao remate para que as persoas asistentes deixasen algún tipo de pagamento (en moeda ou especie) para os artistas (McCormick e Pratasik 2004).

Barriga Verde nace a comezos do século $\mathrm{XX}$ e vén sendo fillo ilexítimo de ambos os dous herdeiros ibéricos de Pulcinella, Roberto e Cristovo. Dos rastrexamentos realizados, complicados pola inexistencia de documentos escritos ou visuais que o confirmen, podemos aventurar que o personaxe foi resultado de confrontar co público galego o heroe portugués. O relato familiar, cotexado coa escasa -ás veces contraditoria- documentación legal existente, permite construír un periplo que levou a familia Silvent, artistas ambulantes de orixe francesa, desde terras estremeñas ao norte portugués e desde alí a Galiza, a onde traerían as artes dos fantocheiros populares que representaban as correrías dos robertos (Iglesias 2013). Na Galiza a única expresión de monifates coñecida até daquela eran os cristovos, que esmorecía a finais do século XIX, cando o escultor Isidoro Brocos fixo o traballo de campo de documentación para a súa peza "el viejo de la Zanfona" (Pereira e Sousa 1991). Segundo as súas notas, recollidas despois por Casto Sampedro y Folgar no seu Cancioneiro, os cegos representaban tras da súa capa, e coa axuda dun mozo, algunhas das escenas típicas do repertorio europeo do teatro de cachaporra europeo. Eran as do barbeiro, o enterro do namorado, a tourada e a pelexa co demo; todas elas presentes, con variantes, no repertorio portugués e no castelán (Sampedro 2007).

Deste xeito, a aparición de Barriga Verde na data aproximada de 1910 non constitúe ningunha innovación ou ruptura, mais a actualización da tradición para garantir a súa supervivencia, adaptándoa ás novas condicións das feiras do primeiro cuarto do século XX. Se ben a mudanza cultural aparellada á implantación do capitalismo foi tardía en Galiza, as feiras e festas das vilas e cidades si se viron influenciadas polas tendencias chegadas da Europa. Así, as actuacións improvisadas de artistas ambulantes entre os postos dará paso ás barracas estables, que, influídas pola moda dos parques de atraccións europeus, pretenden imitar os "pavillóns burgueses", nos que se representa unha serie de números para un público que permanece desde o principio até o fin da actuación (Madrid 1996).

A familia que trae, ou "inventa" a Barriga Verde, pasaría da saba á barraca para adaptarse a esa nova situación, incorporando ao espectáculo as varietés: números cómicos e circenses, canción española e, para rematar, os monicreques de Barriga Verde, que daban nome e sona á barraca. Toda a familia participaba nas actuacións, nas que só puntualmente se incorporaban artistas contratados de fóra, como era habitual nas comunidades ambulantes no período preindustrial. Desta maneira, na primeira metade do século XX prodúcese en Galiza a tensión entre a cultura de masas xurdida da man do capitalismo e a cultura popular da sociedade agraria, unha batalla que xa levaba tempo aberta no resto de Europa, e onde o masivo tiña todas as de ganar. Porén, as culturas populares trataron de sobrevivir á ofensiva conservando os seus contidos esenciais baixo envoltorios aparentemente modernos, unha táctica que Martín Barbero denominou "massmediación" (1991). Sexa como for, o espectáculo de Barriga Verde conseguiu arrastrar ás clases populares co seu espectáculo no que rexurdían os cristovos baixo a pel dun novo personaxe e se incorporaban formas novidosas, ao tempo que antiquísimas, de entretemento.

Tras a interrupción forzada pola guerra civil, o espectáculo continuará a percorrer as principais feiras de Galiza durante os anos máis duros da fame e a represión. Barriga Verde convertiríase en cita obrigada na Pascua padronesa, a Ascensión e o Apóstolo composteláns, a Santa Rita de Vigo, o Corpus ourensán, o Setembro do Carballiño, o San Froilán e as San Lucas de Mondoñedo. Chegan a convivir varias barracas co nome de Barriga Verde, administradas polos tres irmáns Silvent, que tiñan repartidas as súas zonas de influencia: José, residente en Lérez, controla a zona Sur, Santiago móvese pola Mariña e a Costa da Morte e Julia percorre principalmente as zonas de Ourense e Monforte. Nas festas máis importantes, como a Ascensión de Santiago ou o San Froilán de Lugo, coinciden durante algún tempo as barracas de varios irmáns. 
Chegada a década de 1960, comeza o esmorecemento do espectáculo, debido a distintas causas. En primeiro lugar, a avanzada idade dos tres irmáns, que empezan a ter problemas de saúde que lles impiden continuar a actuar. O relevo xeracional non está garantido, xa que ningún fillo desexa continuar cun oficio cada vez máis precarizado. As atraccións mecánicas comezan a centrar a atención nas feiras, constituíndo unha competencia demasiado dura para barracas de varietés, fenómenos ou videntes. E o cinema, que nacera como unha atracción de feira máis, impuxérase a todas elas converténdose no entretemento por antonomasia nas vilas e cidades galegas.

En 1964, na Pascua de Padrón, actúa por última vez a barraca Melodías de España, xerida por José Silvent, o último dos irmáns en activo. Varios dos seus sobriños continuarán a representar os monifates nas aldeas, a onde acudían para proxectar cinema e amenizar os bailes. Mais na década de 1970 Barriga Verde xa non actúa máis. $\mathrm{O}$ aparello franquista promovera un teatro de títeres ao servizo do réxime, e así os personaxes de Gorgorito ou Chacolí, creados por membros da organización xuvenil da Falanxe, van actuar de xeito gratuíto nas prazas das cidades galegas, desvinculados do ambiente das feiras, o que lles fora natural na súa orixe (Ayuso 2015). Ofrecen pezas de corte adoutrinador e moralista, dirixidas a un público eminentemente infantil. O espectáculo dos Silvent era, pola contra, gozado por crianzas e maiores e a única moralidade que podía agochar era a irreverencia, o incomodo perante calquera forma de autoridade, mesmo a divina. Por burlar, Barriga Verde (ao igual que toda a súa parentela europea), burlaba até a Morte.

\section{Un medio de comunicación das subalter- nas}

Este e outros aspectos do repertorio de Barriga Verde leváronme a argumentar, na miña investigación doutoral, que o espectáculo funcionou durante os anos da posguerra como un medio de comunicación dos grupos subalternos na Galiza. Un medio de comunicación, dado que o teatro popular constitúe, por definición, un proceso comunicativo horizontal e en dúas direccións. E un medio dos grupos subalternos -ou das subalternas, se optamos polo xenérico feminino por xustiza histórica- porque a relación de comunicación que se establecía durante as representacións destes espectáculos de monicreques de luva involucraba persoas que non detentaban ningún tipo de poder. $\mathrm{O}$ que non impedía que, nalgunha representación, puidera ter estado presente algunha forza da orde como os membros da Benemérita. Mais estes non participaban do mesmo xeito da relación de comunicación, se a entendemos nas claves do que James Scott definiu como "infrapolíticas" dos grupos subalternos. Segundo o antropólogo estadounidense, en contextos de grave represión da disidencia, os grupos subalternos tenden a xerar un discurso propio, alternativo ao oficial, mais oculto do control gobernamental. Ese discurso oculto permítelles manter a esperanza dun outro futuro, e mesmo artellar formas de resistencia de baixa intensidade, a única posíbel cando as consecuencias da disidencia aberta son irreversíbeis (Scott 1990). Na miña análise do espectáculo de Barriga Verde durante os anos da Posguerra baseeime nos elementos que Scott establece como definitorios de toda forma de resistencia simbólica ou infrapolítica. Non é esta a primeira ocasión na que se atopa acaído o esquema proposto por Scott para traspoñer ao caso galego: os traballos de historiadoras como Ana Cabana (2013) teñen amosado como a sociedade galega mantivo activas moitas destas formas de resistencia de baixa intensidade durante o Franquismo, preferentemente no ámbito rural.

Moitos dos elementos que permiten concluír que o espectáculo de Barriga Verde representou unha forma de resistencia simbólica durante a Posguerra en Galiza non eran exclusivos do espectáculo galego. En moitos casos, proviñan da herdanza europea do personaxe e poderían detectarse nos outros espectáculos da tradición de títeres de cachaporra europeos. Para comezar polo seu carácter anónimo, unha característica que é propia do teatro tradicional de títeres universal. O titiriteiro sempre se agochaba, neste caso por tras dunha tea negra, ocultando a súa figura e xerando así a ilusión de que o boneco tiña vida propia. Non en balde, nas súas orixes a figura do titiriteiro era asociado coa do mago, ou máis aínda, co demiúrgo, quen de volverlle a vida aos seres inertes (Badiou 1988).

Outra das características propias das infrapolíticas é a ambigüidade. Para que a comunicación do descontento, do discurso oculto dos grupos subalternos, sexa viábel e segura, esta debe facerse de tal maneira que a mensaxe só sexa captada por unha parte do auditorio, precisamente con aquela coa que se comparte un universo simbólico alternativo ao hexemónico. Para garantir a seguranza de quen a emite, esa mensaxe precisa ter dous sentidos: 
un superficial, inocuo, que é o que vai percibir aquela parte do auditorio pertencente ao poder, e outro subversivo, codificado. Na miña análise do espectáculo de Barriga Verde puiden detectar esa ambigüidade en distintas escenas, como a combinación de cantos anticlericais (ou a propia malleira ao crego) coa escena final, na que o heroe pide a axuda do público para entoar un Pater Noster como mantra que lle permitirá derrotar ao Demo. Tamén o lema "espectáculo culto y moral" que presidía a barraca durante os anos do Franquismo tiña a ver con esa ambigüidade: un dos requisitos para un espectáculo de feira ser autorizado polas autoridades gobernativas era ser considerado como "moral", mais a familia de titiriteiros optou por incorporala á súa imaxe de marca, nun xiro que a todas luces semella irónico, tendo en conta que o contido do espectáculo pouco tiña que ver co que a ideoloxía Nacionalcatólica incluía na súa acepción de "culto" e de "moral".

Sendo Barriga Verde membro dunha tradición europea de carácter eminentemente carnavalesco, no sentido que Mikhail Bakhtin (2003) lle deu ao termo, son habituais nel as imaxes do mundo ao revés, no que os humildes burlan aos poderosos e as imaxes escatolóxicas abundan. A inversión simbólica é unha das tácticas típicas dos grupos subalternos e está presente en moitas expresións da cultura popular, e tamén nas rimas e cantigas que se entoaban no espectáculo de Barriga Verde. Scott (1990) inclúeas, e por extensión a toda a cultura popular, como a expresión do discurso oculto das clases subalternas, xerada ao longo das xeracións, sen autoría coñecida e transmitida oralmente, unha condición que facilitaba a protección de quen cantaba, interpretaba ou recitaba, que o facía nos momentos máis propicios e nos espazos máis seguros.

Precisamente o espazo das feiras, no que actuaba prioritariamente a barraca de Barriga Verde, era propicio ao relaxamento das normas e do control do poder, o que facilitaba esa comunicación subrepticia do descontento. A feira tradicional galega, herdeira da festa carnavalesca do medievo, consituía o espazo do pobo entendido como todo no que as xerarquías se disolven (Bakhtin 2003: 16). O anonimato da multitude, xunto co intercambio comercial, que situaba á xente nunha base de igualdade, facían do mercado ou da feira un eido no que non se daban nin os rituais de submisión nin a deferencia. Os privilexios suspendíanse (Scott 1990: 123).

\section{4. $O$ resto dun tempo ido}

O feito de constituír un espectáculo de feira, transmitido por artistas ambulantes e dirixido ao público popular, supón un obstáculo para a reconstrución do espectáculo. Os irmáns Silvent eran ágrafos e, ao igual que o resto de titiriteiros da tradición europea, nunca plasmaron por escrito os textos do espectáculo. Cada representación era distinta, modificada en función do lugar e do público asistente. A improvisación facilitaba a impunidade das críticas, ao dificultar o labor da censura.

Cando o espectáculo desaparece na década de 1970, os membros da familia seguen a traballar nas feiras con outros entretementos máis demandados na época: postos de tiro, tómbolas, carruseis e, andando o tempo, atraccións mecánicas (unha actividade na que se manteñen activos algúns dos descendentes dos Silvent). Os monicreques, que outrora constituíran o principal reclamo da atracción, fican abandonados nos faiados, cando non son empregados como diana nos postos de tiro ou como brinquedo para as crianzas da familia. Paulatinamente, os resquicios do espectáculo de Barriga Verde vanse esvaecendo, até que, chegada a década de 1980 , xa só resta a memoria nas persoas que algunha vez asistiron ás representacións.

Prodúcese entón unha fenda na transmisión da tradición, aquela que sobrevivira á caída do Imperio Romano facendo perdurar o arquetipo do labrego zoupón a través dos séculos e das fronteiras e chegara á Galiza transfigurado en Cristovo e finalmente Barriga Verde. A cultura de masas semella ter gañado a batalla e o representante galego da tradición europea de títeres de cachaporra parece condenada á desaparición. Mais na década de 1990 ten lugar en Galiza, ao igual que ocorrera algúns anos antes noutros lugares de Europa, un feito que vai tentar reverter aquel sino tráxico. Unha xeración moza de artistas que queren dedicarse profesionalmente ao teatro de títeres vai tratar de restaurar o elo que estaba a piques de quebrar. Son titiriteiros que se reivindican como tales e desexan asentar o seu oficio nunha tradición, para o que precisan que se lles transmitan os segredos e as técnicas.

\subsection{Primeira fase do proceso de activación patrimonial}

Anxo García, a quen chegou de neno o eco das actuacións de Barriga Verde no seu Lalín natal, é un titiriteiro con interese en asentar a súa 
profesión nunha tradición. Tras moitas pescudas, a finais da década de 1990 localiza un dos legatarios do espectáculo: Alfonso, o fillo máis novo dun dos tres irmáns que representaran o espectáculo de Barriga Verde, José Silvent. Naquela altura reside na casa familiar de Lérez e conserva aínda os bonecos do seu pai. Alfonso Silvent será, até a súa morte en 2016, un dos principais informantes sobre o espectáculo, e unha figura fundamental ao facilitar a transmisión do segredo, algo que durante a vida do pai tería sido imposíbel, pois formaba parte do sistema de protección do modo de vida peripatético (Rao 1985).

Anxo García emprega a información recadada para montar a súa propia versión de Barriga Verde, á que lle incorpora elementos propios, como considera que debe ser tratada a tradición: algo necesariamente vivo e en constante evolución. O espectáculo da compañía "Viravolta", estreado no ano 2000, segue aínda a representarse nos circuítos habituais do teatro de títeres: centros de ensino, teatros municipais e festivais de títeres. É, pois, un contexto de representación ben distinto do orixinal. Neste caso, o público é maioritariamente infantil e os espazos xeran unha distancia maior entre emisor e receptores que a que se producía nas feiras. Probablemente, a mudanza de contexto ocasiona que o espectáculo reciba, de cando en cando, críticas por parte de pais e nais que o consideran violento e transmisor de valores inapropiados. Algo similar ao que lles ocorreu aos membros da compañía andaluza "Títeres desde Abajo", que chegaron a estar en prisión por presunta apoloxía do terrorismo cando representaban unha versión modernizada do espectáculo de Don Cristóbal durante o entroido de 2016 en Madrid (Campoi 2019). Unha mostra de que as claves do universo simbólico carnavalesco pertencen a un mundo desaparecido, o da cultura europea tradicional de base agrícola, que para as modernas sociedades urbanas resulta incomprensíbel.

Deste xeito, o proceso de recuperación de Barriga Verde, durante o que poderiamos cualificar como a activación patrimonial na súa primeira fase, significou a recuperación do espectáculo como repertorio para as artes escénicas, se ben nun sistema cultural ben distinto, moito máis institucionalizado que o orixinal.

\subsection{Segunda fase do proceso de activación patrimonial}

A partir desa primeira acción de reactivación de Barriga Verde, vanse producir outras. Xaime Iglesias, activista cultural de Lérez, recollerá as memorias da familia Silvent asentada neste barrio pontevedrés para reconstruír a biografía dun dos seus membros, José Silvent, así como os testemuños da veciñanza que lembraban ter asistido ás representacións. Froito deste traballo aparecerá o libro Xosé Silvent, o mítico Barriga Verde, editado co apoio do concello pontevedrés (Iglesias 2013).

Paralelamente, con guión de Marcelo Martínez Hermida e Pedro Solla e dirixida por este último, producimos con Tintimán Audiovisual un documental que segue os pasos de Viravolta e entrevista á familia Silvent, ao tempo que amosa a situación dos demais personaxes da tradición europea de títeres de cachaporra. Estreouse en 2011 co título de Morreu o Demo, acabouse a peseta, en referencia á frase coa que remataban sempre as representacións.

Dous anos despois, todas as persoas que illadamente tiñamos participado no proceso de recuperación de Barriga Verde formamos a Asociación Cultural Morreu o Demo. Pretendíase así aglutinar e redobrar todos os esforzos na investigación, preservación, divulgación e socialización do espectáculo. Inician así unha serie de accións diversas: charlas, publicacións (VV.AA. 2013, Campoy e Ermida 2014), até conseguir producir unha exposición de grande formato na que se expuñan os bonecos e algunhas pezas do attrezzo orixinal pertencentes a José Silvent, que Alfonso Silvent acepta emprestar á asociación con este fin. A exposición "Barriga Verde, de feira en feira", consituíu así un fito no labor do colectivo, ao conseguir a complicidade da familia na estratexia de reivindicar o personaxe e o espectáculo como patrimonio colectivo e non restrinxido á esfera do privado. A exposición percorreu distintos espazos expositivos galegos e estatais desde a súa inauguración a finais de 2013, sendo visitada por arredor de 20.000 persoas.

Desde 2016 a Asociación organiza, co apoio da Deputación da Coruña, o festival Titiriberia, no que se programan espectáculos das distintas expresións da tradición europea de monicreques de luva ${ }^{2}$. 
A Asociación Cultural Morreu o Demo vai centrar os seus esforzos en facer ver á sociedade galega o valor de Barriga Verde como patrimonio cultural inmaterial. Iso tradúcese en numerosas accións de divulgación e na continuación dos traballos de pesquisa e recollida iniciados na primeira fase. Xustamente esa reivindicación do valor de Barriga Verde vai xerar un conflito cos descendentes dos titiriteiros, que empezan a presumir que se lle pode tirar un rendemento económico ao legado dos seus devanceiros. Chocan así a concepción democratizadora do colectivo cunha idea do patrimonio como potencial fonte de negocio, que é realmente a forma dominante da categoría hoxe en día.

\section{O patrimonio en cuestión}

Neste punto, quería apresentar a reflexión que me suscita o propio proceso no que estou envolta, de reactivación de Barriga Verde como expresión cultural. Desde hai un tempo teño reticencias a falar de patrimonialización, á luz da revisión crítica que se está a facer do termo desde a Antropoloxía social, nomeadamente por autores como Pablo Alonso González (2017). Para este, a idea de Patrimonio veu da man da modernidade capitalista, que instaurou novas formas de relacionalidade entre as persoas e as cousas, formas basicamente cousificadoras, aniquiladoras das relacións preexistentes que deran sentido aos bens e símbolos que se pretenden incorporar á nova etiqueta. Para Alonso,

el patrimonio sirve como sustitutivo de las «comunidades inmanentes» que existían y que fueron desarticuladas por la modernidad. Sin embargo, la imposible vuelta a estas «comunidades originarias» lleva a un intento de reafirmar la idea de comunidad de forma metacultural, de forma fetichista, mediante símbolos y abstracciones de tipo patrimonial. (2017: 284)

O feito de traballar cun material (sexa este tanxible ou simbólico) que pertence ao pasado (malia os intentos de revivilo no presente), fai que nalgún caso sintamos que se está a producir o fenómeno que Alonso denuncia cando fala de que a relación que predomina con patrimonio é a de inventariado, sanción, selección e institucionalización; isto é, o máis similar ao embalsamamento dun cadáver.

A categoría de patrimonio era completamente allea ao colectivo portador de Barriga Verde, é dicir, os e as feirantes. Tampouco as espectadoras e espectadores de Barriga Verde, maiormente das clases populares, tiñan incorporada esa noción. Nalgúns casos, esas persoas incorporárona a posteriori, asumindo hoxe como patrimonio aquilo que na súa mocidade consideraron un divertimento sen pretensión. Este feito pode considerarse un logro do tecido asociativo en defensa do patrimonio inmaterial, pois por fin se inclúe dentro da categoría patrimonial os bens culturais xerados polas clases populares, deixando a un lado a acepción que até non hai moito tempo fora hexemónica, aquela que identificaba o Patrimonio Histórico Artístico cos bens materiais e monumentais producidos polas clases dominantes e que aínda segue vixente no aparato xurídico da protección patrimonial (Sierra 2000).

Porén, as loitas polo recoñecemento como patrimonio de distintos bens culturais agochan un risco non desprezábel, o da abstracción baixo a etiqueta e o conseguinte alleamento respecto do modo de vida que lle deu sentido na súa orixe.

Lo que los sujetos patrimonializadores representan como primitivo, arcaico y digno de recuperar, es el mundo que otro grupo social habita y da sentido a su experiencia vital. Se genera así una distancia entre el "yo" que clasifica y jerarquiza y el "otro" que es clasificado. (Alonso 2017: 289)

É difícil deixar de sentir que algo do que Alonso denuncia, a partir da súa análise do proceso de activación patrimonial na Maragatería, poida estar ocorrendo con Barriga Verde e a comunidade que lle deu orixe, a feirante. Entre os membros da Asociación Morreu o Demo estase a facer unha revisión crítica do proceso emprendido, poñéndoo baixo "sospeita patrimonial" (Herrero 2018). Se ben en todo momento se partiu dunha noción crítica da categoría patrimonio, reclamando que se considerasen patrimonio as expresións culturais das clases subalternas, sempre contando coa participación das comunidades no proceso, esta participación non sempre se conseguiu, nin está claro que fose positivo para eses bens conseguir esa consideración patrimonial.

Ten senso recuperar unha expresión cultural propia dun contexto social extinguido? Advírtese o risco de fetichizar Barriga Verde, de recuperalo só na forma mais non no seu contido, naquilo que o facía importante para as persoas que o presenciaron no seu momento. Nese senso, será que é imposíbel revivir o seu papel como medio de comunicación das subalternas, como infrapolítica? 
Estas dúbidas, e toda vez que o obxectivo de preservación semella acadado, levan ao colectivo a traballar nun obxectivo que podería contrarrestar os riscos do que Alonso chama a "máquina patrimonial". Isto pasaría por socializar Barriga Verde, é dicir, conseguir que a sociedade galega se reapropie del como símbolo de irreverencia e resistencia ao poder. $\mathrm{O}$ papel da asociación deberá entón limitarse a facilitar esa apropiación por parte de titiriteiros e titiriteiras e das xeracións máis mozas. E nese senso non é tan importante que recuperen a Barriga Verde como espectáculo de monicreques de luva senón como personaxe irreverente e subversivo que non dubida en rirse das figuras da autoridade, sexan cales foran. Desde a asociación tentamos animar, por iso, a que xurdan Barrigas Verdes tanto nas táboas como nas tabletas ou nos móbiles, en Youtube ou en videoxogos. Un requisito fundamental desta socialización será acadar a complicidade das novas xeracións no proceso, para o que se xulga imprescindíbel adaptar o espectáculo ás linguaxes dos novos medios.

Trátase polo tanto de fuxir dunha apropiación esencialista de Barriga Verde como símbolo dunha identidade galega pura e inmutábel. Enténdese que Barriga Verde é un personaxe universal, ou cando menos europeo, co que se identificaron no seu día as clases subalternas da sociedade galega e que podería volver ser referente simbólico do antiautoritarismo contemporáneo.

\section{Activismo vs. máquina patrimonial}

Como conclusión, fronte aos problemas que suscita o patrimonio como categoría susceptíbel de mercantilización e de homoxeneización cultural, oponse a necesidade dun traballo de base que vaia incorporando a acción asociativa desde abaixo.
Nesa liña de traballo atopariamos un exemplo no festival Titiriberia, que a AC Morreu o Demo celebra en $\mathrm{Teo}^{3}$ desde 2016. Coincidindo coa feira cabalar de San Martiño na parroquia de Francos, o festival instala unha recreación da barraca de Barriga Verde, semellante á que a veciñanza de máis idade aínda lembra. A familia Silvent actuaba puntualmente na feira de Francos e a súa memoria segue aínda viva nas persoas maiores da parroquia, que viron con sorpresa como regresaba Barriga Verde á feira. No interior da barraca represéntanse espectáculos de títeres de cachaporra traídos de toda Europa. Deste xeito, recupérase o contexto que lle fora natural ao espectáculo, sen renunciar a innovar nas linguaxes e nos formatos. O importante é manter intacto o contido que está tras o éxito do personaxe e do espectáculo durante séculos: aquel que sacudía os piares do sistema, aínda que os golpes non fosen apenas percibidos por quen detiña o poder. Pois cando Barriga Verde batía na cabeza do crego, non era o dano que puidera facer a cachaporra o que entusiasmaba ao público popular, mais o pracer de se rebelar, aquel que lles estaba vetado. O boneco de madeira canalizaba así os seus desexos máis inconfesábeis, mantiña acesa a chama da revolta. Esta idea é difícil de converter en patrimonio, pois remite a un sentimento imposíbel de escindir do suxeito que o experimenta. Por iso, revivir a Barriga Verde pasa necesariamente por non deixar morrer a súa irreverencia, por buscar outros focos para as súas burlas. E nese proceso deben participar as titiriteiras e titiriteiros que comezan a facer seu o personaxe, e as mozas e mozos que o decidan integrar como referente do seu imaxinario. A función da Asociación pode ser a de impulsar e dinamizar nun primeiro momento, agardando con ansia o momento de facerse a un lado.

\section{Referencias bibliográficas}

Alonso González, Pablo (2017): El Antipatrimonio. Fetichismo y dominación en Maragatería. Madrid: CSIC. Ayuso, Adolfo (2015): "Panorama dos títeres durante o Franquismo", en C. Campoy e G. Ermida (eds.), Barriga Verde, de feira en feira. Santiago de Compostela: Urco, pp. 57-64.

Badiou, Marise (1988): L'ombra i la marioneta o les figures dels déus. Barcelona: Institut del Teatre.

Bakhtin, Mikhail (2003): La cultura popular en la Edad Media y en el Renacimiento en el contexto de François Rabelais. Madrid: Alianza Editorial.

Bernardot, Maurice. (2011): “À la recherche des sans-trace: cultures, espaces et cytoyennetés”, en B. Galinon-Mélénec (dir.), L'Homme-trace. Perspectives anthropologiques des traces contemporaines. Paris: CNRS Éditions, pp. 331-347.

\footnotetext{
En 2020 o festival trasladou a súa sede ao concello de Rianxo.
} 
Cabana, Ana (2013): La derrota de lo épico. Valencia: Publicacions de la Universitat Valenciá.

Campoi, Comba (2014): "La transmission des techniques de jeu parmi les marionnettistes: du secret de famille au copyleft", en Penser les techniques et les technologies: Apports des Sciences de l'Information et la Communication et perspectives des recherces. Toulon: SFSIC, https://sfsic2014.sciencesconf.org/30764/ Sfsic2014_30764.pdf.

(2018): Sen medo ao demo. Resistencia simbólica na Galiza da Posguerra: o teatro de títeres de Barriga Verde. Allariz: Fundación Vicente Risco.

(2019): “Títeres entre rejas. Tácticas infrapolíticas contra el régimen del 78”, en A. I. Arévalo Salinas, G. Vilar Sastre e T. Al Najjer Trujillo (eds.), Estudios interdisciplinarios: paz y comunicación. São Paulo: UNESP e Castellón de la Plana: Combambio, pp. 132-143.

Campoy, Comba e Germám Ermida (eds.) (2015): Barriga Verde, de feira en feira. Santiago de Compostela: Urco.

Herrero, Nieves (2018): “O estado da cuestión”, en Xornada Retos na xestión do patrimonio inmaterial. Santiago de Compostela: Consello da Cultural Galega, http://consellodacultura.gal/evento.php?id=200695.

Hobsbawn, Eric (1984): The invention of tradition. Cambridge: Cambridge University Press.

Iglesias González, Xaime (2013): José Silvent Martínez, o mítico Barriga Verde. Compostela: Urco.

Madrid Álvarez, Juan Carlos de la (1996): Cinematógrafo y "Varietés" en Asturias (1896-1915). Oviedo: Servicio de Publicaciones del Principado de Asturias.

Magnin, Charles (1862): Historie des marionnettes en Europe depuis l'Antiquité jusqu'à nos jours. París: Levy-frères.

Martín-Barbero, Jesús (1991): De los medios a las mediaciones. Barcelona: Gustavo Gili.

McCormick, John e Bennie Pratasik (2004): Popular puppet theatre in Europe, 1800-1914. Cambridge: Cambridge University Press.

Montano, Agnelio (2003): Pulcinella. Dal mimo classico alla masquera moderna. Napoli: Dante\&Descartes.

Pereira, Fernando e José Sousa (1991): “O ‘cego dos monifates' de Isidoro Brocos”, Anuario Brigantino 14, pp. 289-300.

Rao, Aparna (1985): "Des nómades méconnus. Pour une typologie des communautés péripatétiques", L'Homme 25/95, pp. 97-120.

Sampedro Folgar, Casto (2007): Cancionero musical de Galicia. Reconstitución y estudio de José Filgueira Valverde. Pontevedra: Fundación Barrié de la Maza.

Scott, James C. (1990): Domination and the Arts of Resistance. Hidden trascripts. New Haven and London: Yale University Press.

Sierra, Xosé Carlos (2000): "Procesos de patrimonialización en Galicia”, en X. González Reboredo, Galicia. Antropoloxía. Tomo XXIX. Historia da Antropoloxía. Patrimonio etnográfico. A Coruña: Hércules, pp. 380-472.

VV.AA. (2013): Morreu o Demo, acabouse a peseta (libro-DVD). Compostela: Urco. 